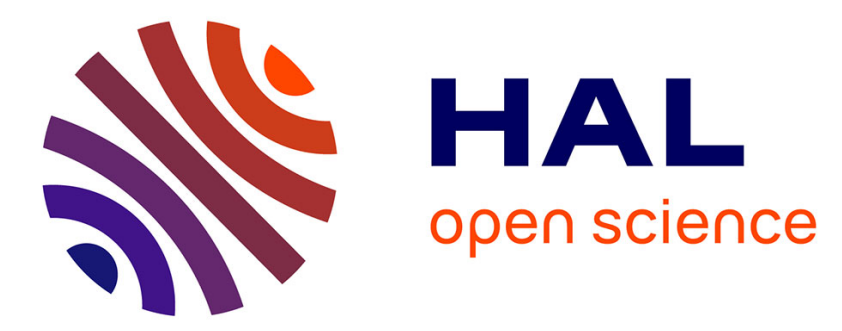

\title{
Development of online separation and surfactant quantification in effluents from an enhanced oil recovery (EOR) experiment
}

Elie Ayoub, Perrine Cologon, Marie Marsiglia, Jean-Baptiste Salmon, Christine Dalmazzone

\section{To cite this version:}

Elie Ayoub, Perrine Cologon, Marie Marsiglia, Jean-Baptiste Salmon, Christine Dalmazzone. Development of online separation and surfactant quantification in effluents from an enhanced oil recovery (EOR) experiment. Journal of Petroleum Science and Engineering, 2022, 208 (Part D), pp.109696. 10.1016/j.petrol.2021.109696 . hal-03426472

\section{HAL Id: hal-03426472 \\ https://hal.science/hal-03426472}

Submitted on 12 Nov 2021

HAL is a multi-disciplinary open access archive for the deposit and dissemination of scientific research documents, whether they are published or not. The documents may come from teaching and research institutions in France or abroad, or from public or private research centers.
L'archive ouverte pluridisciplinaire HAL, est destinée au dépôt et à la diffusion de documents scientifiques de niveau recherche, publiés ou non, émanant des établissements d'enseignement et de recherche français ou étrangers, des laboratoires publics ou privés. 
1 Development of online separation and surfactant

2 quantification in effluents from an Enhanced Oil

3 Recovery (EOR) experiment

4 AUTHOR NAMES

5 Elie Ayoub $^{\mathrm{a}}$, Perrine Cologon*a, Marie Marsiglia ${ }^{\mathrm{a}}$, Jean-Baptiste Salmon ${ }^{\mathrm{b}}$, Christine $^{*}$

6 Dalmazzone $^{\mathrm{a}}$

7

8 AUTHOR ADDRESS

$9{ }^{\text {a }}$ IFP Energies nouvelles, 1 et 4 avenue de Bois-Préau, 92852 Rueil-Malmaison, France

$10 \quad{ }^{\mathrm{b}}$ Laboratoire du futur - UMR5258, 178 avenue du Dr. Schweitzer, 33600 Pessac, France 
15 Both the growth of global oil consumption and the decline of new conventional oil fields 16 discoveries are observed (Bera and Mandal, 2015; Hirasaki et al., 2011; Thomas, 2008; Sheng,

17 2014). To match the current oil demand, reservoir recovery rate must be increased. Conventional

18 oil production methods, namely first and secondary recovery, lead together to the recovery of

19 around 20 to $40 \%$ of the original oil in place (Bera and Mandal, 2015; Hirasaki et al., 2011;

20 Thomas, 2008; Sheng, 2011; Sheng, 2014). Then, the flow rate of produced oil tends towards zero,

21 partly due to the action of capillary forces that traps the residual oil in the pores of the reservoir

22 (Reed and Healy, 1977). The dimensionless capillary number Ca expresses the ratio of viscous

23 drag forces to capillary forces. It has been experimentally demonstrated that the residual oil

24 saturation in the reservoir decreases as this capillary number increases (Hakiki et al., 2017; Lake,

25 1989; Oughanem et al., 2015). Consequently, the action of capillary forces can be counterbalanced

26 in several ways into the pores of the reservoir. It is possible to increase the injection velocity or

27 the viscosity of the moving water phase by using solutions of polymers. However, these solutions

28 are quickly limited by practical aspects related to the injection power of the pumps and the risks

29 of rock fracking. Thus, the best way to significantly increase the capillary number is the reduction

30 of the interfacial tension between oil and water (IFT) by several decades. This drastic reduction is

31 obtained by using specific chemical surfactants within a tertiary recovery technique called

32 surfactant chemical EOR (cEOR) or "surfactant flooding" (Sheng, 2011). This process consists in

33 injecting a surfactant formulation which lowers the IFT between water and oil and thus facilitates

34 the oil mobilization towards the producing wells (Bourrel and Schechter, 1988; Jing et al. 2021;

35 Hirasaki et al. 2011; Sheng, 2010). In the case of sandstone reservoirs, anionic surfactants are

36 essentially employed, due to their low tendency to adsorb on negatively charged surfaces (Chen 
37 and Schechter, 2021). The main chemical structures are sulfates, like alkyl sulfates, alcohol ethoxy

38 or propoxy sulfates and sulfonates, like alkyl aryl sulfonates, linear or branched alkyl benzene

39 sulfonates, alpha-olefin or internal olefin sulfonates (Negin et al., 2017).

40 The formulation of the surfactants, which is the key parameter of surfactant flooding, is

41 specifically designed to achieve ultra-low IFT (lower than $10^{-2} \mathrm{mN} / \mathrm{m}$ ) and create a Winsor III

42 microemulsion (WIII) with the oil at reservoir temperature (Haegel et al., 2008; Hakiki et al., 2015;

43 Salager et al., 2013; Thomas et al., 1999). Winsor III system can be achieved by balancing the

44 respective affinities of the hydrophobic and hydrophilic parts of the surfactants with regard to the

45 aqueous and oily phases. The formulation design is therefore performed through salinity-scan

46 tests, which are generally used to investigate the phase diagrams of anionic surfactant formulations

47 (Hirasaki et al., 2011). From a practical point of view, salinity modifies the distribution of the

48 anionic surfactant between the oil, brine and microemulsion phases (Fukumoto et al., 2016;

49 Fukumoto et al., 2018; Salager et al., 2013). Below the optimal salinity, the surfactant is preferably

50 soluble in brine, giving a Winsor I system (WI), consisting of an oil-in-water microemulsion in

51 equilibrium with an excess of oil phase. At a salinity higher than the optimum, it preferably

52 becomes soluble in the oily phase, giving a Winsor II system (WII), consisting of a water-in-oil

53 microemulsion in equilibrium with an excess of aqueous phase. At the optimal salinity $\mathrm{S}^{*}$, the

54 surfactant is mainly concentrated in the intermediate microemulsion phase, giving a Winsor III

55 system consisting of a bicontinuous microemulsion in equilibrium with the excess aqueous and

56 oily phases. It is noteworthy that the IFT is the lowest at this optimal salinity.

57 Most of the time, the optimal formulation can be first developed through robotic salinity-scan tests

58 (AlSofi et al., 2021; Morvan et al., 2008). This is essentially done on model oil phases (alkanes)

59 representative of the Equivalent Alkane Carbon Number (EACN) of the crude oil under 
60 investigation (Queste et al., 2007). In a final step, the formulation is optimized with the real crude

61 oil (Oukhemanou et al., 2014).

63 The efficiency of the designed formulation is then evaluated using a test called "coreflood 64 experiment". This refers to a specific setup which operates on a rock sample under pressure and 65 temperature conditions very close to those of the reservoir (Flaaten et al., 2009; Hirasaki et al., 66 2011; Levitt et al., 2009; Mohammadi et al., 2009). The measurement of the quantity of oil 67 recovered and of surfactants retained on the rock makes it possible to determine the performance 68 of the surfactant flooding process, hence the efficiency of the formulation, the environmental 69 footprint and the profitability of the process. Evaluating the economics of the process and 70 environmental footprint are of paramount importance. For these two parameters, it is worthwhile

71 to recover the highest volume of oil by injecting the lowest amount of surfactants, meaning that 72 most of surfactants must be adsorbed on the water-oil interface and only a negligible part on the

73 rock. Therefore, the volume of oil produced by surfactant flooding and the quantity of surfactant

74 adsorbed on the rock must be determined for each coreflood experiment. The effluents resulting

75 from a coreflood test are complex mixtures of oil, brine and surfactants. They are generally 76 collected in graduated cylinders or tubes as the experiment progresses. The analyses are then 77 performed a posteriori, offline. The quantity of oil recovered is calculated from volumetric 78 measurements (estimation of the water-to-oil volume ratio in each tube) or by a NMR analysis of 79 the rock sample at the end of the test (Fleury and Deflandre, 2003). The presence of quite stable 80 emulsions in the tubes induces a lower accuracy of the volumetric measurement. The concentration 81 of surfactants is measured in the aqueous phase using various techniques such as potentiometric 82 Hyamine titration (Liu et al., 2010), high performance liquid chromatography (HPLC), or even 
83 UV-visible spectroscopy, though offline (Liang et al., 2021). It is noteworthy that carrying out

84 these analyses is a tremendous challenge, especially for the determination of the surfactant

85 concentration. A main issue concerns the presence of emulsions in the effluents that can sometimes

86 be very stable (Dalmazzone et al., 2012). The type of these emulsions is generally oil-in-water and

87 the presence of micronic oil droplets may interfere with the Hyamine dosage or foul the liquid

88 chromatography column. Another trouble comes from the distribution of surfactants between the

89 oily and aqueous phases. Depending on the experimental conditions, it is possible that the

90 surfactants are partly trapped in the oil phase. These surfactants are not quantified in the mass

91 balance, which may lead to an overestimation of the quantity of surfactants adsorbed or retained

92 on the rock and consequently to the rejection of a formulation for economic and environmental

93 reasons.

94 To overcome these difficulties, a micro/millifluidic device capable of treating and separating 95 coreflood effluents online has been designed. This setup allows a relevant quantification of the

96 surfactant concentration, online or offline. The overall approach consists in (1) performing an

97 online dilution of the effluent with deionized water to decrease the salinity and thus promote

98 surfactant transfer to the aqueous phase, (2) separating online the oil and the aqueous phase using

99 a membrane, and (3) measuring the surfactant concentration.

100

101 In this paper, the designed micro/millifluidic setup is detailed. The validation of the methodology

102 was first performed on a model system of surfactants and oil. Then, the whole micro/millifluidic

103 assembly was tested at the outlet of a real coreflood experiment to evaluate the potential of the

104 developed methodology in realistic and representative conditions. 


\subsection{Chemicals}

108 Sodium dodecylbenzenesulfonate (SDBS) (technical grade) was purchased from Sigma-Aldrich.

109 Isobutanol $\left(\mathrm{C}_{4} \mathrm{H}_{10} \mathrm{O}\right)$ with $>99 \%$ purity and n-decane $\left(\mathrm{C}_{10} \mathrm{H}_{22}\right)$ with $99 \%$ wt purity were provided 110 by Alfa Aesar. Sodium chloride $(\mathrm{NaCl})$ with $99.9 \%$ purity was purchased from VWR chemicals. 111 Organol Red was obtained from Prolabo. All compounds were used without further purification. 112 Aqueous solutions were prepared with Milli-Q water (resistivity higher than $18.2 \mathrm{M} \Omega / \mathrm{cm}$ ). The 113 industrial surfactants, Alkylglyceryl Ether Sulfonate (AGES - 33wt.\% active matter) and Internal 114 Olefin Sulfonate (IOS - 33wt.\% active matter), were provided by Solvay. Arabian light crude oil, 115 filtered over $5 \mu \mathrm{m}$, was chosen in this study because of its low paraffin content, avoiding clogging 116 of the tubings at room temperature. Details of the Arabian light composition and characteristics 117 are given in Table 1.

118

119 Table 1. Density and viscosity at $20^{\circ} \mathrm{C}$ and SARA composition of the Arabian light crude oil

\begin{tabular}{|cc|}
\hline Density at $\mathbf{2 0}^{\circ} \mathrm{C}(\mathrm{g} / \mathrm{cm} 3)$ & 0.88 \\
Viscosity at $\mathbf{2 0}^{\circ} \mathrm{C}(\mathbf{m P a} . \mathbf{s})$ & 12 \\
Saturates (wt\%) & 53.8 \\
Aromatics (wt\%) & 32.6 \\
Resins (wt\%) & 10.6 \\
Asphaltenes (wt\%) & 2.7 \\
\hline
\end{tabular}


122 Phase diagrams are of interest in order both to optimize EOR formulations through the

123 identification of the optimal salinity and to treat the effluent with the appropriate methodology.

124 While WIII microemulsions are the aim of EOR formulation design, WI microemulsions are

125 preferred to treat the effluents as the surfactant is mainly contained in the aqueous phase for such 126 systems.

127 Model fluid mixtures were prepared with decane and an aqueous phase composed of Milli-Q water, 128 SDBS, $\mathrm{NaCl}$ brine and isobutanol. SDBS is a sulfonate anionic surfactant. It was selected because 129 it is a representative surrogate for EOR surfactants due to its sulfonate polar moiety and its carbon 130 chain length, and also because its aromatic ring makes UV-visible absorption measurement 131 possible. Fluids representative of real systems were prepared with filtered Arabian light crude oil 132 and an aqueous phase composed of Milli-Q water, an industrial IOS-AGES blend and $\mathrm{NaCl}$ brine. 133 For both systems, salinity scans were done to determine the different Winsor zones. 134 Microemulsions were prepared at room temperature in glass tubes using the following procedure.

135 - First, solutions of SDBS $(16 \mathrm{~g} / \mathrm{L})$ and $\mathrm{NaCl}(200 \mathrm{~g} / \mathrm{L})$ were prepared in separate flasks. The 136 mass of SDBS and $\mathrm{NaCl}$ was measured with an electronic weighing scale (AE200, Mettler 137 Toledo) with a precision of $\pm 0.1 \mathrm{mg}$.

138 - Then, $3.5 \mathrm{~mL}$ of the SDBS solution was added in a glass tube. Also, $0.40 \mathrm{~mL}$ of isobutanol 139 (5.83 \%vol. of aqueous phase) was added to ensure the dissolution of the surfactants.

140 - Next, the volume of the aqueous phase was adjusted to $7 \mathrm{~mL}$ with Milli-Q water and $\mathrm{NaCl}$ 141 solutions whose respective volumes enable to achieve the set salinity (ranging from 15 to $14280 \mathrm{~g} / \mathrm{L})$. At that point, the solution was carefully mixed. 
- Finally, $7 \mathrm{~mL}$ of decane was poured along the glass tube walls, resulting in a Water to Oil Ratio (WOR) of one. The interface was gently stretched by turning the tubes upside down approximately 6 times without creating an emulsion.

- Then, the samples were left for one month at room temperature to ensure complete thermodynamic equilibrium.

Middle phases corresponding to Winsor III systems were observed for salinities ranging from 28 to $52 \mathrm{~g} / \mathrm{L}$ (Figure 1). The phase transitions can be described as follows: Winsor I type microemulsion (oil-in-water) from 0 to $25 \mathrm{~g} / \mathrm{L} \mathrm{NaCl}$, Winsor III (bicontinuous) from 28 to 52 $\mathrm{g} / \mathrm{L} \mathrm{NaCl}$, and Winsor II (water-in-oil) from 55 to $80 \mathrm{~g} / \mathrm{L} \mathrm{NaCl}$, in agreement with previous studies (Fukumoto et al., 2016).

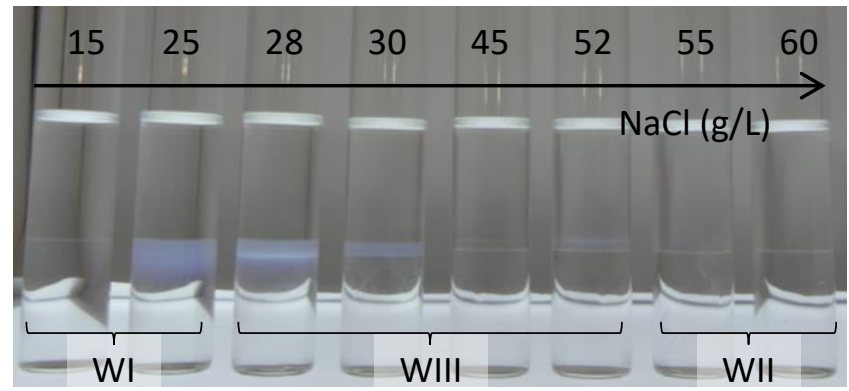

154 Figure 1. Photograph of formulated microemulsions with salt increments. Formulations are 155 composed of water, $\mathrm{NaCl}, \mathrm{SDBS}$, isobutanol and decane. WOR is unity. WI, WII and WIII are the 156 abbreviations of Winsor I, II and III respectively.

158 The same protocol was followed for the microemulsions formulated with crude oil and industrial 159 surfactants. Decane was replaced by Arabian Light crude oil and a $4 \mathrm{~g} / \mathrm{L}$ solution of IOS-AGES 160 mixture was used instead of SDBS. Note that isobutanol was not used in this case and the WOR 161 was set to 0.7 . The samples were kept at $40{ }^{\circ} \mathrm{C}$ during four months in order to reach equilibrium. 162 A middle phase was observed for salinities ranging from 70 to $75 \mathrm{~g} / \mathrm{L}$. Phase transitions in terms 
163 of microemulsions can be described as follows: Winsor I (oil-in-water) from 0 to $65 \mathrm{~g} / \mathrm{L} \mathrm{NaCl}$,

164 Winsor III (bicontinuous) from 70 to $75 \mathrm{~g} / \mathrm{L} \mathrm{NaCl}$, and Winsor II (water-in-oil) from 80 to $130 \mathrm{~g} / \mathrm{L}$

$165 \mathrm{NaCl}$.

166

$167 \quad 2.3$ Water-in-oil titration

168 Mass fraction of water in the oil phase or the microemulsion phase was measured by Karl Fischer

169 titration. The titration was conducted with 787-KF Titrino from Metrohm with a reagent of

170 Hydranal-Composite 5 purchased from Fluka. A weighed sample (about $10 \mathrm{mg}$ ) was injected into

171 a measuring cell, and the amount of water in the sample was obtained from the volume of reagent

172 needed to reach a significant shift in potential. All the samples were analyzed at least three times.

173

$174 \quad 2.4$ Surfactant quantification

175 Different techniques were used to measure the concentration of surfactant in the aqueous phase.

176 Conventional offline analyses included Hyamine titration and High-performance liquid

177 chromatography (HPLC).

178 For Hyamine titration, $1 \mathrm{~mL}$ of the sample was introduced in the measuring cell of the titrator

179 (862-compact Titrosampler, Metrohm). Incremental volumes $(30 \mu \mathrm{L})$ of titrant (Hyamine 1622-

180 solution, Merck Millipore) were added to the sample until a shift in potential was reached.

181 HPLC analysis was also employed to confirm the results of Hyamine titration. Briefly, samples

182 were injected into an Agilent 1260 Infinity system coupled to an Evaporative Light Scattering

183 Detector (ELSD G4260B). A mixture of ammonium acetate buffer $(\mathrm{pH}=5)$ and acetonitrile was

184 used as mobile phase at a flow rate of $1 \mathrm{~mL} / \mathrm{min}$. Once separated, the surfactants were detected in 
185 the ELSD (nebulization temperature: $40^{\circ} \mathrm{C}$, evaporator temperature: $70^{\circ} \mathrm{C}$ ). Both analytical 186 techniques were calibrated with standard solutions.

187 Additionally, online measurements were specifically developed: UV-visible absorption spectra 188 were acquired on an AvaSpec-ULS2048 spectrophotometer (Avantes) equipped with a deuterium189 halogen light source offering a wavelength range of $200 \mathrm{~nm}$ to $1100 \mathrm{~nm}$. A micro-flow cell $(18 \mu \mathrm{L}$ 190 volume) with a $10 \mathrm{~mm} \mathrm{Z-design} \mathrm{optical} \mathrm{path} \mathrm{was} \mathrm{used} \mathrm{for} \mathrm{online} \mathrm{measurements} \mathrm{(Avantes).}$

\section{$192 \quad 2.5$ Micro/Millifluidic experimental setup}

193 Low pressure syringe pumps neMESYS 290N (Cetoni) were used to pump the fluids. Teflon 194 tubings from Cluzeau Info Labo (1/16" external diameter and $762 \mu \mathrm{m}$ internal diameter) were 195 used to connect all parts of the setup. Oil-in-water emulsions were created with two coaxial 196 capillaries. The chip was manufactured by inserting a circular capillary with a $200 \mu \mathrm{m}$ internal 197 diameter in a square capillary of $400 \mu \mathrm{m}$ internal width. This enables to create oil-in-water 198 emulsions at the tip of the inner capillary in the continuous aqueous phase (Utada et al., 2005).

199 Decane was colored with organol red for visualization purposes.

200 The membrane separation device is sold by Dolomite under the name "Membrane Chip Interface" 201 and is specifically designed for online liquid-liquid separation. It consists of two microfluidic glass 202 chips engraved on one side, a hydrophilic treated PTFE membrane (Part No. 3200347, Dolomite) 203 and a metal structure which seals the whole system. Each glass chip consists of a serpentine 204 channel with a length of $21.2 \mathrm{~cm}$, width of $900 \mu \mathrm{m}$ and height of $150 \mu \mathrm{m}$. The hydrophilic 205 membrane ( $25 \mathrm{~mm}$ in diameter and $0.2 \mu \mathrm{m}$ nominal pore size) is sandwiched between the two 206 chips. It contains four inlets, two on each side of the membrane, to ensure the insertion of the tubes 207 allowing the connections. In our case, one of the bottom inlets was closed in order to have one 
208 inlet on the upper side and two outlets on both sides of the membrane. Outlets are referred to as

$209 \mathrm{O} 1$ and $\mathrm{O} 2$ for the upper and lower sides respectively. The whole system is schematically presented

210 in Figure 2.

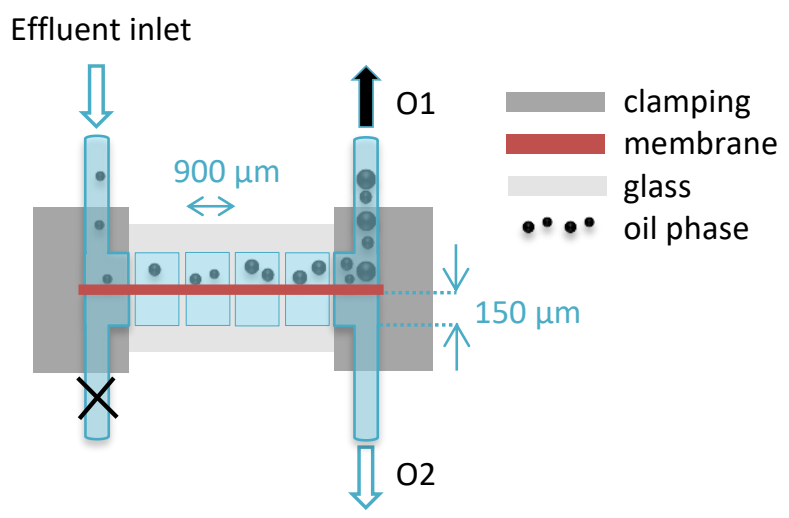

212 Figure 2. Schematic sectional view of the membrane separation device. The membrane stands in 213 red and both outlets for the separated effluent are identified (O1 and $\mathrm{O} 2)$. The black circles

214 correspond to droplets of oil transported in the flowing aqueous phase (light blue).

215

216 Visualization of the fluids circulating in the system is partly possible thanks to a small opening in

217 the metal structure.

\section{$219 \quad 2.6$ Coreflood experiment}

220 A coreflood experiment setup, designed at IFPEN and schematically presented in Figure 3, was

221 used with a "Bentheimer" type core (38.9 mm long and $34.98 \mathrm{~mm}$ in diameter). This sandstone

222 outcrop sample is often used to mimic reservoir behavior for EOR studies. The core is placed in a

223 sleeve in a coreholder Hassler cell. An overburden pressure is then applied on the sleeve to ensure

224 that no leak occurs between the core and the sleeve. All the experiments were carried out at a pore

225 pressure of $10 \mathrm{bar}$ and a confining pressure of 40 bar. Temperature was kept at $40^{\circ} \mathrm{C}$ throughout

226 the experiment. 


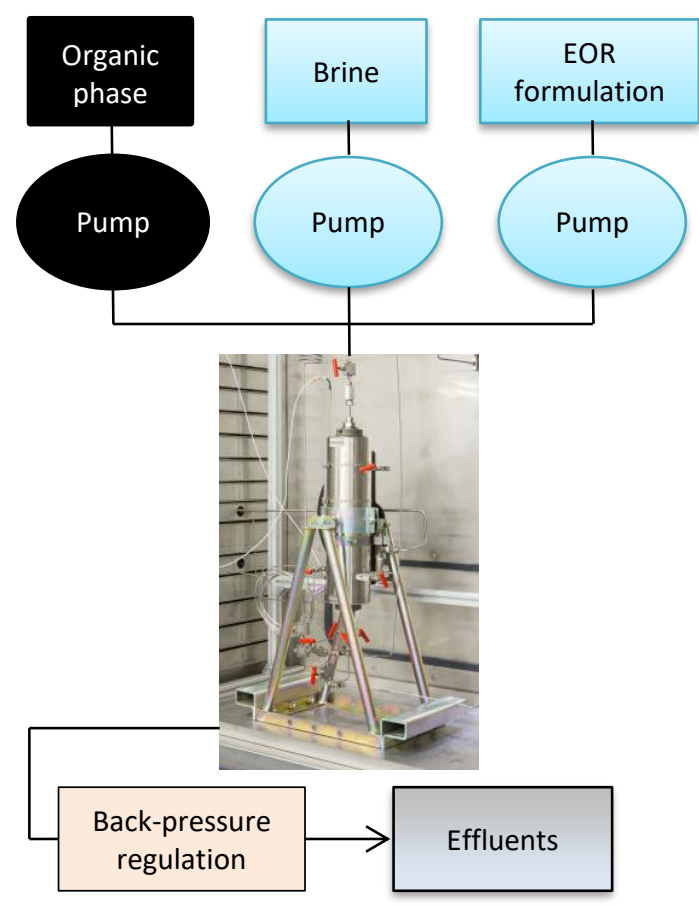

228 Figure 3. Schematic view of a coreflood experiment.

230 General EOR workflow has been described in details elsewhere (Moreau et al., 2010). Briefly, the

231 following steps were applied: first of all, a forced imbibition step was performed with brine to 232 determine the pore volume of the core $(28.1 \mathrm{~mL})$. In a second step, the rock was saturated with a 233 filtered Arabian Light crude oil. Then, water injection was carried out to mimic a "waterflooding" 234 step in order to determine the residual oil saturation $(56 \%$, i.e. $15.7 \mathrm{~mL}$ of oil). Finally, the 235 formulation was injected at a flow rate of $5 \mathrm{~mL} / \mathrm{h}$ for 52 hours, followed by a brine injection at 70 $236 \mathrm{~g} / \mathrm{L} \mathrm{NaCl}$ for 50 hours. 
The purpose of this study is to develop a method leading to accurate measurement of surfactant

240 concentrations in EOR effluents. Therefore, an efficient oil/water separation is needed. A dilution

241 with water is also performed as a first step to decrease the salinity and switch the aqueous phase

242 of the effluent to a Winsor I microemulsion because surfactants are mostly in the aqueous phase

243 in this case.

244 Figure 4 displays a schematic view of the experimental setup developed to achieve these steps

245 online. The whole assembly includes an effluent collection or generation with coaxial capillaries

246 for model experiments to optimize the following steps (Figure 4.a), a dilution step (Figure 4.b), a

247 membrane separation device (Figure 4.c) and an online UV-visible absorption measurement

248 (Figure 4.d). Each step has been individually optimized, before assembling and characterizing the

249 whole setup.

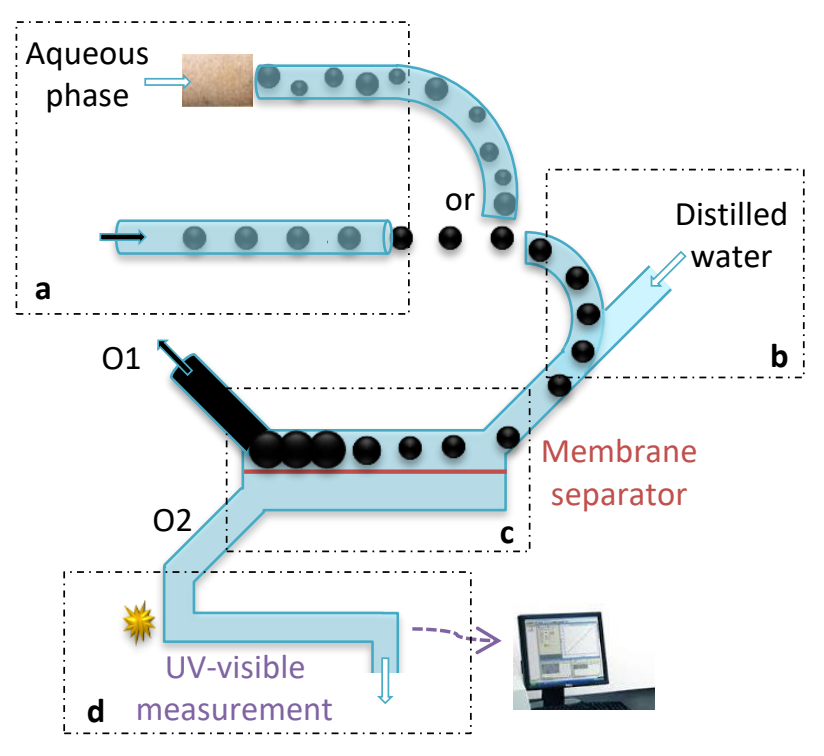

251 Figure 4. Schematic view of the experimental setup developed in this study. It includes: a. effluent 252 collection or generation with coaxial capillaries, b. dilution with distilled water, c. membrane 253 separation and d. UV-visible absorption measurement. The black circles show schematically oil 254 droplets flowing in the aqueous phase (light blue).

\subsection{Oil-in-water emulsion creation}


257 Surrogate oil-in-water emulsions were obtained with coaxial capillaries (Figure 4.a). Water flow

258 rate ranged from 1 to $10 \mathrm{~mL} / \mathrm{h}$ which is representative of flooding conditions. Droplet size could

259 easily be tuned by modifying the oil flow rate relatively to the one of water. For this study, the

260 flow rate of the aqueous continuous phase was always twice the one of the organic phase. This

261 resulted in oil droplets having a mean diameter of about $400 \mu \mathrm{m}$.

\section{$263 \quad 3.2$ Dilution step}

264 The effluent, either created by coaxial capillaries or collected at the outlet of the coreflood, was

265 then diluted with Milli-Q water (Figure 4.b) using a syringe pump and a T-junction. The dilution

266 water flow rate was equivalent to the initial flow rate of the water phase in the emulsion. This step

267 enabled to reduce the salinity by a factor of two and thus highly increased the IFT between the

268 aqueous phase and oil, promoting phase separation. In a first attempt, a microfluidic herringbone

269 design was used to maximize the mixing efficiency as described in the work of Stroock et al.

270 (2002). However, in this configuration, oil droplets were sheared into smaller droplets which

271 limited the oil/water separation likely due to the fouling of the membrane. A simple T-junction

272 appeared to be sufficient to dilute the effluent.

\section{$274 \quad 3.3$ Membrane separation device}

275 The oil/water separation step is represented schematically in Figure 4.c and detailed previously in

276 Figure 2. Due to the hydrophilic nature of the membrane, the fluid in outlet $\mathrm{O} 2$ is expected to be

277 mostly aqueous, whereas the fluid in outlet $\mathrm{O} 1$ is expected to be composed of a mixture of organic 278 and aqueous phases. 


\subsection{Surfactant quantification}

281 Online UV-visible absorption spectroscopy was developed in the framework of this study as a 282 quantification technique of the surfactants in aqueous samples (Figure 4.d). UV-visible spectra 283 obtained for different concentrations of SDBS are shown in Figure 5. The absorbance at $267 \mathrm{~nm}$ $284\left(\lambda_{0}\right)$ exhibited a linear relationship with SDBS concentrations (see the insert of Figure 5) according 285 to the Beer-Lambert law, whatever the salinity (0 to $10 \mathrm{~g} / \mathrm{L} \mathrm{NaCl}$ ). The choice of this wavelength 286 to monitor SDBS is explained in the next sections.

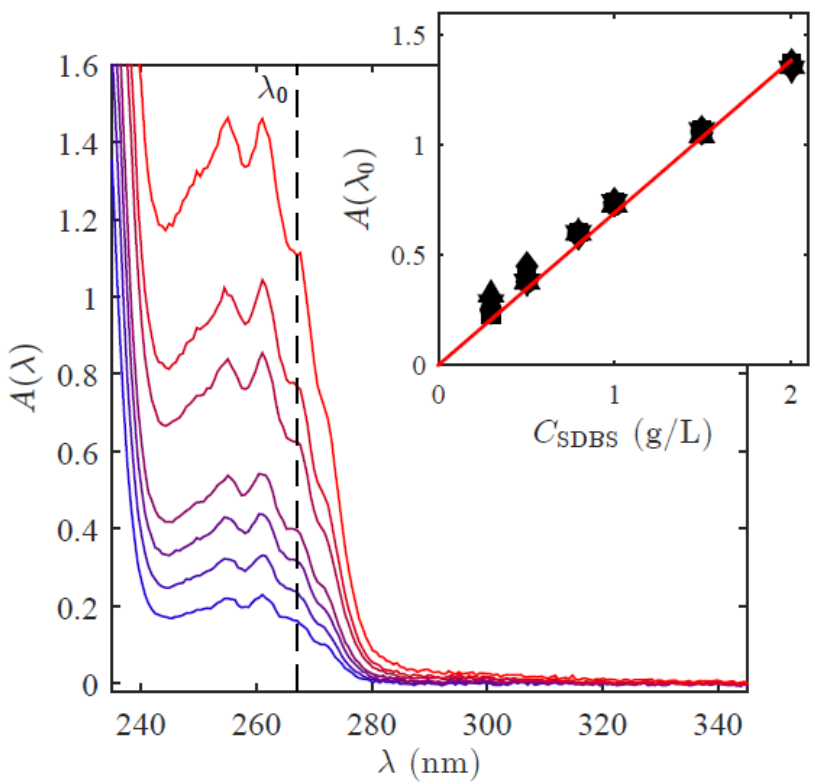

Figure 5. Absorbance $(A(\lambda))$ for different concentrations of SDBS in Milli-Q water at room temperature; Insert : Absorbance $\mathrm{A}\left(\lambda_{0}\right)$ at the wavelength $\lambda_{0}=267 \mathrm{~nm}$ chosen to monitor SDBS concentration.

293 First, the impact of the interfacial tension between the aqueous phase and decane on the membrane 294 separation efficiency has been studied. Therefore, different Winsor I emulsions, corresponding to 
295 different interfacial tensions, were formed and injected directly in the separation device using the 296 coaxial capillary device. Then, the injection was stopped to immobilize the fluids in the device, 297 and O1 was closed. In this configuration the fluid can only flow through the membrane and the 298 objective of this experiment was to determine the pressure at which the decane breakthrough 299 occurs. Thus, different pressures were applied at the inlet of the device (pressure controller MFCS300 EZ, Fluigent) while observing the membrane area under a stereomicroscope using the opening of 301 the Dolomite membrane device (see insert in Figure 6 for a typical image using bright-field 302 imaging).

303 At low imposed pressures, decane droplets are getting closer and some of them coalesce. At a well304 defined critical transmembrane pressure drop $P_{c}$, one clearly sees decane droplets starting to flow 305 through the membrane.

306 The interfacial tensions were measured with a Krüss SDT spinning drop tensiometer. These 307 experiments showed that for an emulsion with an interfacial tension of $35.7 \pm 0.2 \mathrm{mN} / \mathrm{m}$, the 308 breakthrough pressure is about $\sim 135 \mathrm{kPa}$. For an emulsion with an IFT of $3.6 \pm 0.4 \mathrm{mN} / \mathrm{m}$, the 309 breakthrough pressure decreases down to about $\sim 22.5 \mathrm{kPa}$. And this pressure decreases further 310 down to about $\sim 12.5 \mathrm{kPa}$ for an IFT of $1.4 \pm 0.1 \mathrm{mN} / \mathrm{m}$. These data are plotted in Figure 6 . 


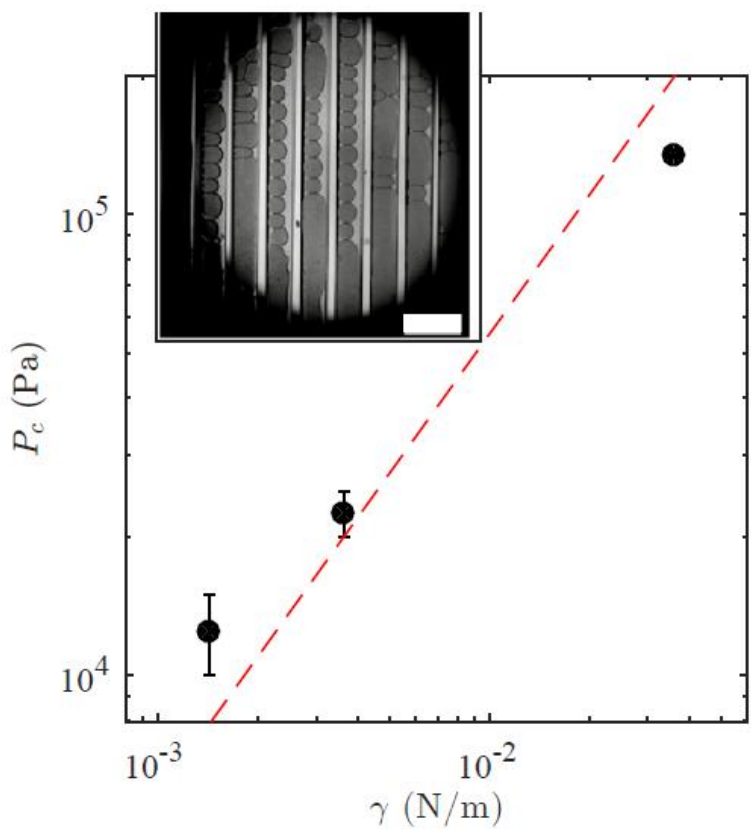

312 Figure 6. Breakthrough pressure $\left(\mathrm{P}_{\mathrm{c}}\right)$ of the decane through the hydrophilic membrane versus 313 interfacial tension $(\gamma)$. The red dashed line is the linear law $P_{c}=2 \gamma / r$ with $r=0.4 \mu$ m. Insert: 314 bright-field image of the membrane separation device taken with a stereomicroscope before 315 applying pressure at the inlet.

317 Capillary pressure is related to the interfacial tension of the fluids according to the application of

318 Young-Laplace equation in a narrow tube of circular cross-section with a zero contact angle giving

319 the capillary pressure $2 \gamma / r$, with $\gamma$ the interfacial tension $(\mathrm{N} / \mathrm{m})$ and $r$ the pore radius of the 320 membrane (m). So, for a constant pore size, as a first approximation, the breakthrough pressure $P_{c}$ 321 is proportional to the IFT. Figure 6 shows the experimental data, as well as the best linear fit of 322 the breakthrough pressure according to $P_{c}=2 \gamma / r$. While this relationship does not perfectly fit 323 our data, this crude estimate yields a pore size of $0.4 \mu \mathrm{m}$ in agreement with the value given by the 324 manufacturer $(0.2 \mu \mathrm{m})$ considering the complex geometry of the pores. Without being predictive, 325 these data allow us to determine the range of pressure for which we can be sure that the oil droplets 326 do not pass through the membrane for a given IFT. 
328 The second characterization of the membrane separation device was to check its ability to separate

329 an emulsion with flow rates ranging between 1 and $10.5 \mathrm{~mL} / \mathrm{h}$, in the same order of magnitude as

330 the flow rates usually used for coreflood experiments. For this purpose, a Winsor I emulsion was

331 created with the model system (with decane being colored with organol red for the ease of

332 visualization) and injected in the membrane separation device at different flow rates. The fluids

333 recovered at the two outlets were collected in flasks. Two phases were recovered at Outlet 1: a red

334 phase and a pink one (Figure 7.b); but only one phase in Outlet 2, a pink one (Figure 7.c). The red

335 phase of $\mathrm{O} 1$ is decane and the pink phase of $\mathrm{O} 1$ and $\mathrm{O} 2$ is mainly water. Its pink coloration is due

336 to the presence of SDBS at a concentration higher than the critical micellar concentration, which

337 allows the dispersion of organol red, insoluble in water without SDBS. Similar behaviors were

338 observed for three different flow rates $(1.5,4.5$, and $10.5 \mathrm{~mL} / \mathrm{h})$ at various salinities $(0,5,10$, and

$33915 \mathrm{~g} / \mathrm{L}$ ). Note that all the tested salinities lead to Winsor I microemulsions at thermodynamic

340 equilibrium.

341 Figure 7.a shows the water percentage measured by Karl-Fisher titration, versus the emulsion flow

342 rate at the entrance of the separation device. Water content was measured in the upper phase (red

343 oily phase) recovered in $\mathrm{O} 1$ and in the aqueous phase recovered in $\mathrm{O} 2$. Initial fluids were also

344 analyzed, giving the results in red $(Q=0 \mathrm{~mL} / \mathrm{h})$. These values $(92 \% \pm 6 \%$ for aqueous phase -

345 below the quantification limit for the organic phase) were in agreement with the expected 346 concentrations. 


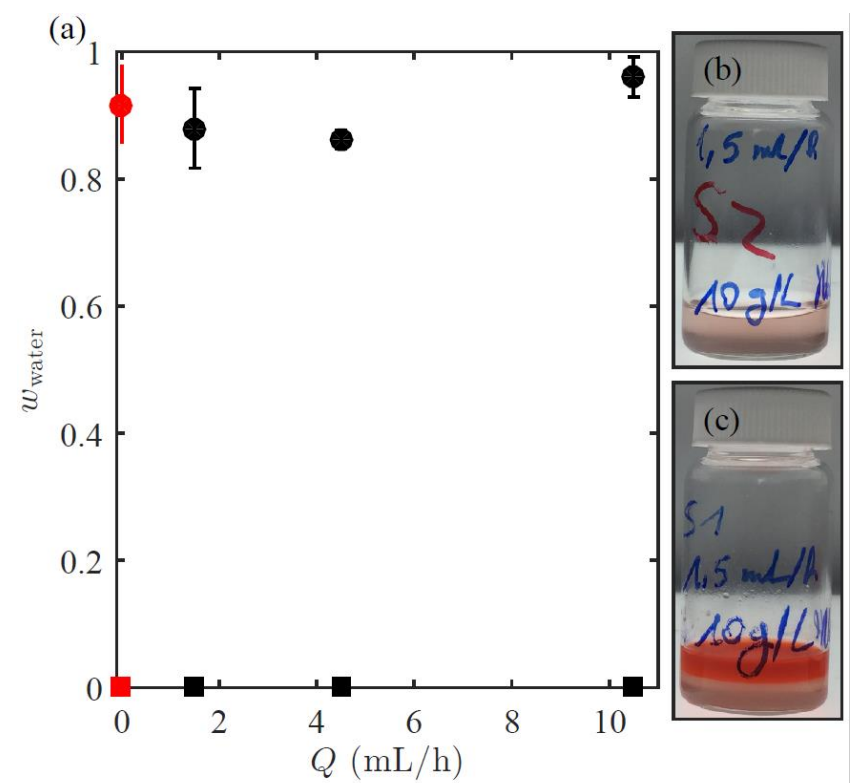

348 Figure 7. a. Water content $\left(\mathrm{w}_{\text {water }}\right)$ measured by Karl Fischer titration in the supernatant oily 349 phase at Outlet 1 (black square) and in the aqueous phase at Outlet 2 (black circle) after separation 350 with the membrane separation device. The water content of the initial phases is specified in red 351 (red square for decane and red circle for the aqueous solution of SDBS). Pictures of b. Outlet 2 352 flask and c. Outlet 1 flask.

354 In O2 (black circles) water contents comprised between 88 and $96 \%$ vol were obtained, depending 355 on the injection flow rate. Concerning the upper phase of O1, Karl Fisher titration gives the same 356 result as the initial decane, which allows us to claim that the red phase is pure decane. Therefore, 357 the membrane separation device leads to a $>90 \%$ pure aqueous phase, which is considered 358 satisfactory regarding the final application.

\section{$360 \quad$ 3.6 Characterization of the full experimental setup}

361 This section aims at evaluating the potential of the proposed methodology for separating the

362 organic and aqueous phases and measuring the surfactant concentration in the aqueous phase. So 363 the complete setup was assessed, including dilution, oil/water separation and surfactant 
364 quantification. Results obtained with either model fluids or real systems are presented in this 365 section.

366 First, experiments were performed with SDBS concentrations of $0.5,1$ and $1.5 \mathrm{~g} / \mathrm{L}$, and salinities

367 equal to 5,10 , and $15 \mathrm{~g} / \mathrm{L}$; at these salinities, Winsor I microemulsions are obtained at equilibrium.

368 Figure 8 shows the concentrations of SDBS measured after oil/water separation at three different

369 flow rates $(1.5,4.5$, and $10.5 \mathrm{~mL} / \mathrm{h})$ for 9 formulations containing initially various amounts of

$370 \mathrm{NaCl}$ and SDBS. SDBS concentrations presented in Figure 8 are the average of 8 measurements

371 performed online with the UV-visible spectrometer at $267 \mathrm{~nm}$ during an hour. The measured

372 concentrations are around $10 \%$ lower than the expected concentrations. This difference could be

373 due to the presence of small oil droplets that can pass through the membrane because the tested

374 salinities lead to a Winsor I microemulsion (cf. next paragraph), leading to a different

375 spectroscopic response. To confirm the SDBS concentration, the separated aqueous phase was also

376 measured by Hyamine titration. The results show that the initial concentrations of $0.5 \pm 0.05$,

$3771 \pm 0.05$, and $1.5 \pm 0.04 \mathrm{~g} / \mathrm{L}$ were obtained.

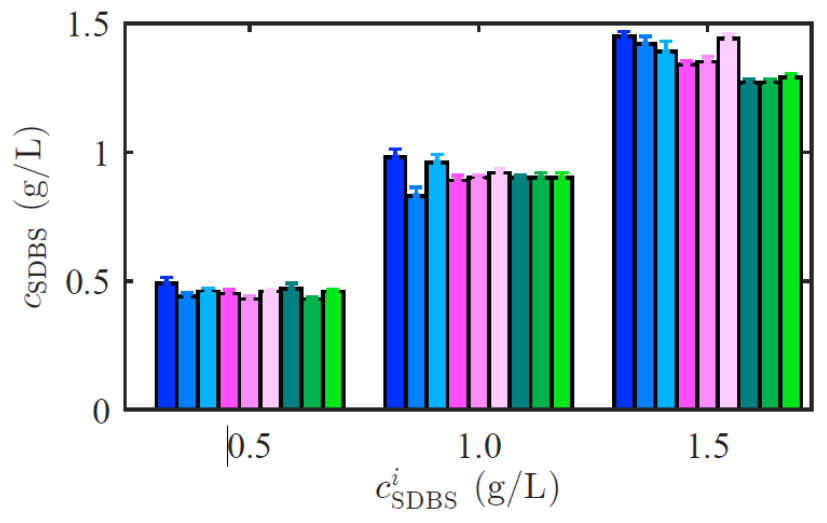

379 Figure 8. SDBS concentrations $\left(c_{\mathrm{SDBS}}\right)$ in the phase obtained in Outlet 2 measured with UV380 visible spectroscopy, after separation with the membrane separation device for different flow rates $381(1.5,4.5$, and $10.5 \mathrm{~mL} / \mathrm{h}$ from dark to light color), different salinities $(5 \mathrm{~g} / \mathrm{L}$ in blue, $10 \mathrm{~g} / \mathrm{L}$ in pink, $38215 \mathrm{~g} / \mathrm{L}$ in green) and different initial SDBS concentrations $\left(c_{\mathrm{SDBS}}^{\mathrm{i}}\right)$. 
384 Both UV-visible measurements and Hyamine titration results show that in the case of the model 385 systems, a reliable online surfactant measurement at $\pm 10 \%$ can be obtained.

386 Furthermore, experiments were carried out to assess potential interactions between the aqueous 387 phase containing surfactants and decane possibly resulting in changes in the UV-visible spectra. 388 Comparisons were made between a raw $1 \mathrm{~g} / \mathrm{L}$ SDBS solution in $5 \mathrm{~g} / \mathrm{L} \mathrm{NaCl}$ (blue spectrum in 389 Figure 9) and the same solution contacted with decane for seven days at room temperature (red 390 spectrum in Figure 9).

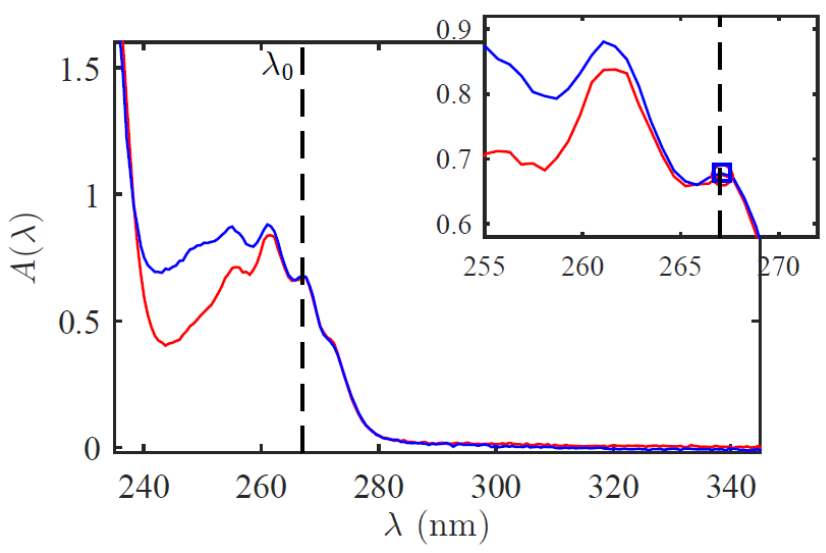

392 Figure 9. Absorbance $\mathrm{A}(\lambda)$ of a $1 \mathrm{~g} / \mathrm{L}$ SDBS solution in $5 \mathrm{~g} / \mathrm{L} \mathrm{NaCl}$ before (blue) and after (red) 393 contacting decane at room temperature.

395 A significant decrease in absorbance was observed in the $240-260 \mathrm{~nm}$ range. This might be 396 explained by the formation of micelles in the aqueous phase, which bias the measurement. These 397 objects have been quantified by Dynamic Light Scattering (DLS) showing that their size is around $39820 \mathrm{~nm}$ in diameter. This observation led us to select a wavelength providing a constant signal for 399 the SDBS quantification (267 nm, Figure 9). 
400 Secondly, the performance of the whole experimental setup was assessed with real systems:

401 filtered Arabian light crude oil and an aqueous phase composed of an industrial blend of surfactants

402 at concentrations of 1,2 , and $4 \mathrm{~g} / \mathrm{L}$ at a salinity of $35 \mathrm{~g} / \mathrm{L}$. At this salinity, a Winsor I microemulsion

403 is obtained. Table 2 shows the concentrations measured with Hyamine titration at three different

404 flow rates $(1.5,4.5$, and $10.5 \mathrm{~mL} / \mathrm{h})$. The obtained concentrations are in good agreement with the

405 expected ones.

Table 2. Industrial surfactant concentrations in the phase obtained in Outlet 2 measured with Hyamine titration, after separation with the membrane separation device for different flow rates $408(1.5,4.5$ and $10.5 \mathrm{~mL} / \mathrm{h})$ at a salinity of $35 \mathrm{~g} / \mathrm{L}$.

409

\begin{tabular}{|c|c|c|c|}
\hline \multirow{2}{*}{$\begin{array}{c}\text { Expected industrial } \\
\text { surfactant } \\
\text { concentration }(\mathrm{g} / \mathrm{L})\end{array}$} & \multicolumn{3}{|c|}{ Measured industrial surfactant concentration } \\
\cline { 2 - 4 } & $1.5 \mathrm{~mL} / \mathrm{h}(\mathrm{g} / \mathrm{L})$ & $4.5 \mathrm{~mL} / \mathrm{h}(\mathrm{g} / \mathrm{L})$ & $10.5 \mathrm{~mL} / \mathrm{h}(\mathrm{g} / \mathrm{L})$ \\
\hline 1 & $1.1 \pm 0.1$ & $1.1 \pm 0.1$ & $1.1 \pm 0.1$ \\
\hline 2 & $2.1 \pm 0.2$ & $2.1 \pm 0.2$ & $2.1 \pm 0.2$ \\
\hline 4 & $3.7 \pm 0.4$ & $3.7 \pm 0.4$ & $3.9 \pm 0.4$ \\
\hline
\end{tabular}

411 These results confirm that the experimental setup is efficient to separate the effluents (oil-in-water

412 emulsions), enabling accurate quantification of surfactants in the aqueous phase with offline

413 measurements, here Hyamine titration.

414 Note that no online UV-visible measurement could be exploited during these experiments because

415 the contact between crude oil and water phase containing surfactants resulted in the dispersion of

416 compounds from the oil. Spectra were so altered in this case that no reliable quantification could

417 be considered. 
420 The implementation of our experimental setup on a coreflood experiment is presented in Figure 42110.

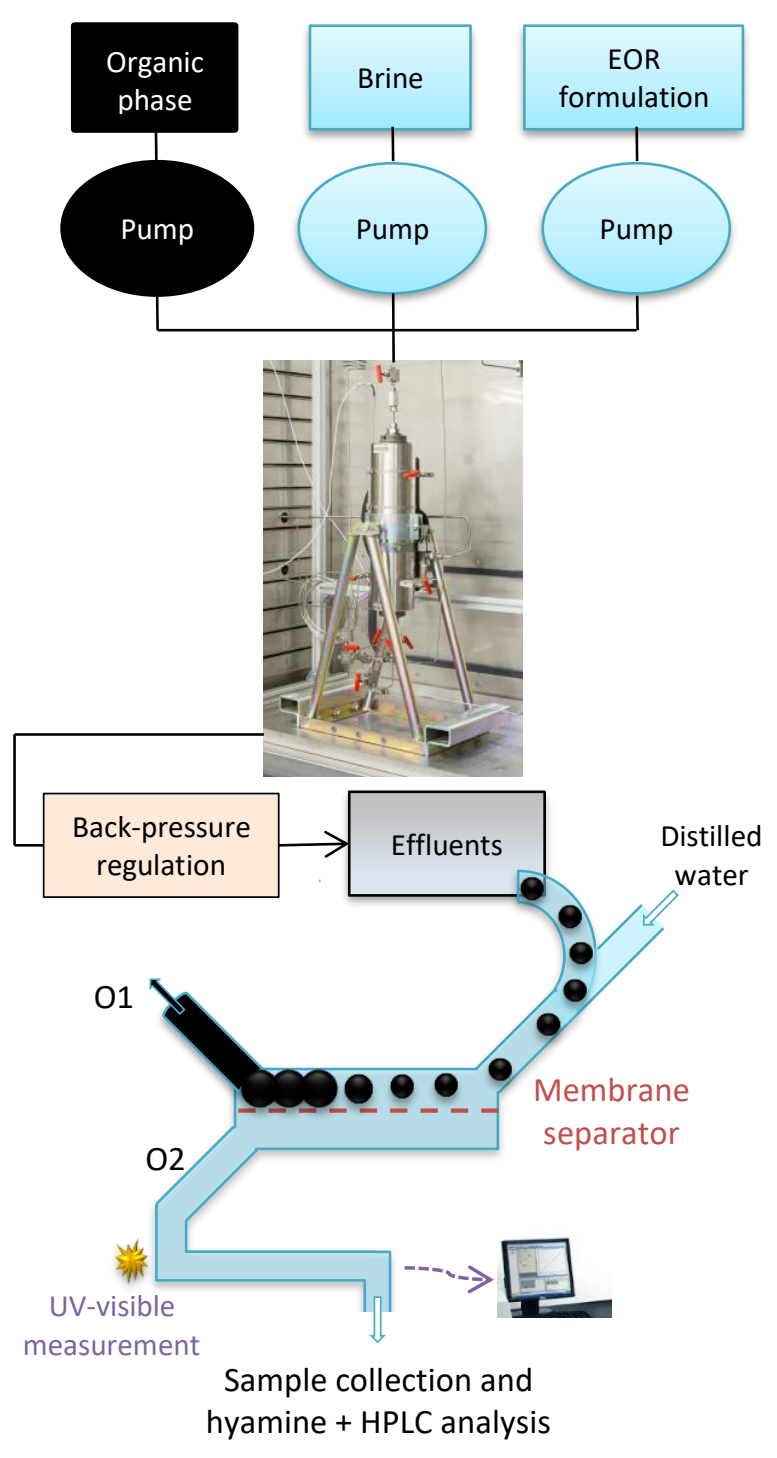

423 Figure 10. Schematic view of a coreflood experiment and downstream implementation of our 424 experimental setup.

426 The formulation for surfactant flooding was optimized through a salinity scan with $\mathrm{NaCl}$ from a 427 mixture of surfactants composed of $4 \mathrm{~g} / \mathrm{L}$ of AGES and $4 \mathrm{~g} / \mathrm{L}$ of IOS, both provided by Solvay. 428 The optimal $\mathrm{NaCl}$ salinity leading to WIII microemulsions is about $70 \mathrm{~g} / \mathrm{L}$ at $40^{\circ} \mathrm{C}$. 
429 While the formulation was injected, the effluents of the coreflood experiment were diverted into

430 the microfluidic setup, located after the back-pressure regulation (Figure 10). After dilution with

431 water and separation, the aqueous phase was pumped into to the UV-visible spectroscopy flow cell

432 and an autosampler which collected the fluids at a frequency of 1 tube per hour for offline

433 surfactant measurements.

434 Only one phase was recovered at the aqueous outlet $\mathrm{O} 2$ of the membrane separation device (Figure

435 11.b), while a mixture of oil and water was collected in the oily outlet O1. No free oil phase was

436 seen, nor any phase separation, in the tubes of $\mathrm{O} 2$, even one month after the end of the experiment.

437 Evolution of the color of the effluents collected at Outlet 2 was noticed throughout the experiment.

438 The samples changed from transparent in the beginning to a pale yellow color that gets darker, and

439 at the end samples gradually became transparent again. This color change could be related to the

440 formation of an oil-in-water microemulsion with very tiny droplets (a few tens of nm droplets as

441 shown before) that can flow through the pores of the separation membrane.
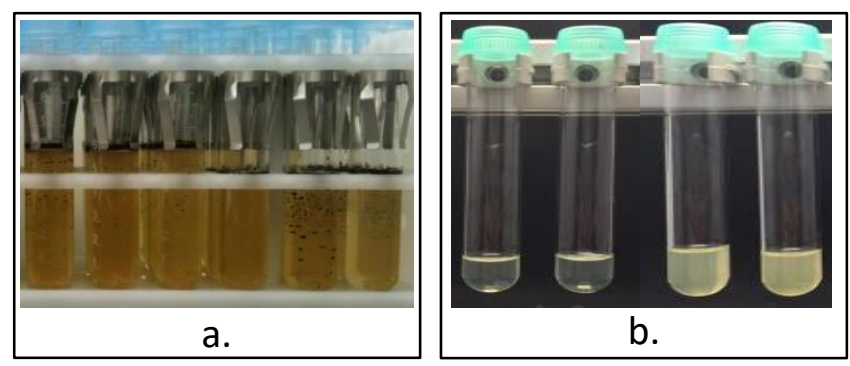

443 Figure 11. Aspect of the coreflood effluents once collected in tubes: a. without using our 444 experimental setup, b. after using our experimental setup in the aqueous outlet (Outlet 2). A clear 445 improvement of water quality is noticed thanks to the present setup.

447 This water quality is compatible with an offline determination of the surfactants by Hyamine 448 titration and by HPLC under completely satisfactory conditions without further purification steps. 
Figure 12 shows the evolution of the surfactant concentrations measured offline in the separated 450 water phase, as a function of injected porous volume $\left(V_{p}\right)$. Results of both analyses (Hyamine 451 green triangles, and HPLC - purple triangles) are quite consistent.

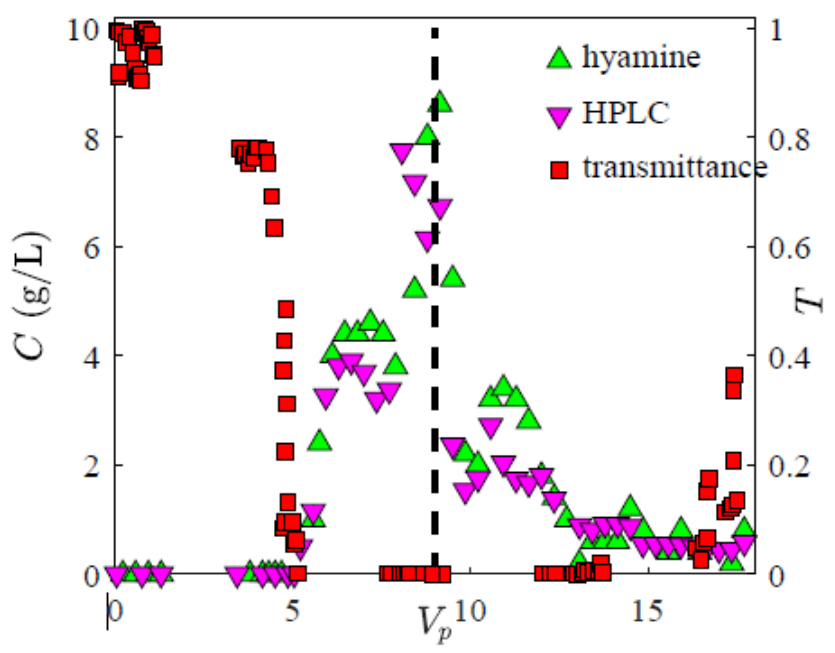

453

454 transmission mode. The evolution of the transmittance measured online at a wavelength of $255 \mathrm{~nm}$

464 is superimposed in Figure 12. A clear breakthrough of surfactants corresponds to the point where 465

Figure 12. Analysis of the separated aqueous effluents from the coreflood: Evolution of the concentration of industrial surfactants (C) measured by Hyamine titration (green triangle) and HPLC (purple triangle) and evolution of the transmittance at $255 \mathrm{~nm}$ (red square) vs. injected porous volume $\left(V_{p}\right)$. The dotted line stands for the end of the surfactant injection step.

It is important to note that online measurement by UV-visible spectroscopy cannot be used to quantitatively monitor surfactant concentration due to the presence of other interfering substances, as previously mentioned above. However, it can advantageously be used to follow the breakthrough of surfactants and identify their presence in specific samples generated throughout the coreflood experiment. In this case it is necessary to use the information obtained in the transmittance falls to zero. As long as the effluents contain surfactant, the transmittance value remains close to zero, and then begins to increase again as the surfactant concentration itself 
467 becomes negligible. This information can advantageously be used to select the relevant tubes for 468 further offline analysis.

469 This experiment led us to the conclusion that the experimental setup makes it possible to obtain a 470 "clean" aqueous phase (i.e. containing no free oil) from the effluents for the quantification of

471 surfactants. The quality of this aqueous phase enables to provide accurate results using offline 472 techniques (Hyamine titration, HPLC) and avoids the time-consuming manual oil/water separation

473 step. Moreover, the use of online UV-visible spectroscopy analysis allows an online monitoring

474 of the surfactant presence which is a significant improvement over the current protocols where this 475 information is obtained retrospectively.

\section{CONCLUSIONS}

477 In this work, a micro/millifluidic setup was developed with the aim of quantifying online the 478 surfactant concentration at the outlet of a coreflood experiment. The experimental setup includes: 479 a dilution chip to transfer the surfactants in the water phase, a membrane-based separation device, 480 and an online UV-visible absorption spectrometer for surfactant monitoring.

481 The performance of the membrane separation device was first evaluated. The range of pressure for 482 which an oily phase does not flow through the membrane was determined depending on the 483 interfacial tension. In this pressure range, the performance of the membrane separation device was 484 assessed with various flow rates ( 1 to $10 \mathrm{~mL} / \mathrm{h}$ ) and salinities (0 to $15 \mathrm{~g} / \mathrm{L} \mathrm{NaCl}$ ). The fluid 485 collected downstream the membrane contains around $90 \%$ water, confirming the efficiency of the 486 device over a wide range of operating conditions. 
488 The whole experimental setup was then successfully tested on model fluid mixtures (decane, $\mathrm{NaCl}$

489 brine and SDBS) and real systems (Arabian Light oil, $\mathrm{NaCl}$ brine and a mixture of IOS-AGES).

490 The membrane separation device allowed a very efficient separation of oil-in-water emulsions and

491 it was possible to accurately measure the concentration of surfactants in the separated aqueous

492 phase.

493 The setup was finally implemented downstream a coreflood experiment to test its efficiency under

494 industrial conditions. The oil/water separation proved to be efficient, providing an aqueous phase

495 compatible with further offline analyses like potentiometric Hyamine titration or HPLC. The direct

496 online surfactant measurement with UV-visible spectroscopy was unfortunately prevented by the

497 presence of interferences due to the contact with crude oil. However, the transmittance signal could

498 advantageously be exploited to continuously follow the breakthrough of surfactants and target the

499 relevant samples for offline analyses, which is clearly an improvement compared to classical

500 protocols. Table 3 summarizes the upgrading reached thanks to the experimental setup developed

501 in the present study.

502 Table 3. Improvements obtained in the present study, compared to classical monitoring 503 approaches

\begin{tabular}{|c|c|c|}
\hline & Classical methods & $\begin{array}{c}\text { Improvements obtained in the } \\
\text { present study }\end{array}$ \\
\hline Oil/water separation & Offline gravity separation & Online membrane separation \\
\hline Surfactant analysis & Offline & Online/Offline \\
\hline $\begin{array}{c}\text { Surfactant analysis } \\
\text { technique }\end{array}$ & Potentiometric titration & $\begin{array}{c}\text { UV-visible (online) or HPLC } \\
\text { (offline) }\end{array}$ \\
\hline $\begin{array}{c}\text { Measurement } \\
\text { accuracy }\end{array}$ & $\begin{array}{c}\text { Low: (1) poor oil/water separation } \\
\text { leading to high uncertainties, (2) } \\
\text { part of the surfactant remains } \\
\text { trapped in the oil phase and is } \\
\text { therefore not quantified. }\end{array}$ & $\begin{array}{c}\text { Greatly improved: (1) very low } \\
\text { residual oil amounts, (2) the } \\
\text { dilution step enables to transfer all } \\
\text { surfactant in the aqueous phase. }\end{array}$ \\
\hline
\end{tabular}


506 AUTHOR INFORMATION

507 Author Contributions

508 The manuscript was written through contributions of all authors. All authors have given approval

509 to the final version of the manuscript.

510 ACKNOWLEDGMENT

511 Solvay is acknowledged for providing the industrial surfactants. 
REFERENCES

513 AlSofi A.M., Miralles V., Rousseau D., Dokhon W.A. (2021) An all-inclusive laboratory 514 workflow for the development of surfactant/polymer formulations for EOR in harsh carbonates, Journal of Petroleum Science and Engineering 200, 108131. DOI: https://doi.org/10.1016/j.petrol.2020.108131

Bera A., Mandal A. (2015) Microemulsions: A novel approach to enhanced oil recovery: a review, J Petrol Explor Prod Technol 5, 3, 255-268. DOI: https://doi.org/10.1007/s13202-014-01395

Bourrel, M. and Schechter, R.S. (ed.) (1988) Microemulsions and Related Systems: Formulation, Solvency and Physical Properties, Marcel Dekker, New York. DOI: https://doi.org/10.1080/01932699008943264

Fukumoto A., Dalmazzone C., Frot D., Barré L., Noïk C., Dalmazzone C. (2018) Characterization of Complex Crude Oil Microemulsions-DSC Contribution, Oil \& Gas Science and

Chen W. and Schechter D.S. (2021) Surfactant selection for enhanced oil recovery based on surfactant molecular structure in unconventional liquid reservoirs, Journal of Petroleum Science and Engineering 196, 107702. DOI: https://doi.org/10.1016/j.petrol.2020.107702

Dalmazzone C., Noïk C., Argillier J.-F. (2012) Impact of Chemical Enhanced Oil Recovery on the Separation of Diluted Heavy Oil Emulsions, Energy Fuels 26, 6, 3462-3469. DOI: https://doi.org/10.1021/ef300083z

Flaaten A.K., Nguyen Q.P., Pope G.A., Zhang J. (2009) A Systematic Laboratory Approach to Low Cost, High Performance Chemical Flooding, SPE reservoir Evaluation and Engineering 12, 5, 713-723. DOI: https://doi.org/10.2118/113469-PA

Fleury M., Deflandre F. (2003) Quantitative Evaluation of Porous Media Wettability Using NMR Relaxometry, Magnetic Resonance Imaging 21, Special Issue // 3-4, 385-387. DOI: $10.1016 / \mathrm{s} 0730-725 \times(03) 00145-0$

Fukumoto A., Dalmazzone C., Frot D., Barré L., Noïk C. (2016) Investigation on Physical Properties and Morphologies of Microemulsions formed with Sodium Dodecyl Benzenesulfonate, Isobutanol, Brine, and Decane, Using Several Experimental Techniques, Energy Fuels 30, 6, 4690-4698. DOI: https://doi.org/10.1021/acs.energyfuels.6b00595 Technology - Rev. IFP Energies nouvelles 73, 4, 3. DOI: https://doi.org/10.2516/ogst/2017039 
543 Haegel F.-H., Lopez J.C., Salager J.L., Engelskirchen S. (2008) Microemulsions in Large Scale 544 Applications, in Microemulsions: Background, New Concepts, Applications, Perspectives, Stubenrauch C. (ed.), Wiley_Blackwell.

Hakiki F., Ayuda Maharsi D., Marhaendrajana T. (2015) Surfactant-Polymer Coreflood Simulation and Uncertainty Analysis Derived from Laboratory Study, Journal of Engineering and Technological Sciences 47 ,

6, $\quad$ 706-724.

DOI: https://doi.org/10.5614/j.eng.technol.sci.2015.47.6.9

Hakiki F., Aditya A., Ulitha D.T., Shidqi M., Adi W.S., Wibowo K.H., Barus M. (2017) Well and Inflow Performance Relationship for Heavy Oil Reservoir under Heating Treatment, SPE 186187 in SPE/IATMI Asia Pacific Oil \& Gas Conference and Exhibition, Jakarta, Indonesia, October 2017. DOI: https://doi.org/10.2118/186187-MS

Hirasaki G.J., Miller C.A., Puerto M. (2011) Recent Advances in Surfactant EOR, SPE Journal 16, 04, 889-907. DOI: https://doi.org/10.2118/115386-PA

Jing W., Fu S., Zhang L., Li A., Ren X., Xu C., Gao Z. (2021) Pore scale experimental and numerical study of surfactant flooding for enhanced oil recovery, Journal of Petroleum Science and Engineering 196, 107999. DOI: https://doi.org/10.1016/j.petrol.2020.107999

Lake L.W. (ed.) (1989) Enhanced Oil Recovery, Prentice Hall, Englewood Cliffs, N.J. ISBN: $0132816016,9780132816014$.

Levitt D.B., Jackson A.C., Heinson C., Britton L.N., Malik T., Dwarakanath V., and Pope G.A. (2009) Identification and Evaluation of High-Performance EOR Surfactants, SPE reservoir Evaluation and Engineering 12, 2, 243-253. DOI: https://doi.org/10.2118/100089-PA

Liang T, Zhao X., Yuan S., Zhu J., Liang X., Li X., Zhou F. (2021) Surfactant-EOR in tight oil reservoirs: Current status and a systematic surfactant screening method with field experiments, Journal of Petroleum Science and Engineering 196, 108097. DOI: https://doi.org/10.1016/j.petrol.2020.108097

Liu S., Li R.F., Miller C.A., Hirasaki G.J. (2010) Alkaline/Surfactant/Polymer Processes: Wide Range of Conditions for Good Recovery, SPE Journal 15, 02, 282-293. DOI: https://doi.org/10.2118/113936-PA

Mohammadi H., Delshad M., Pope G.A. (2009) Mechanistic Modeling of ASP Floods, SPE reservoir Evaluation and Engineering 2, 4, 518-527. DOI: https://doi.org/10.2118/110212-PA 
Moreau P., Morvan M., Rivoal P., Bazin B., Douarche F., Argillier J.-F., Tabary R. (2010) An Integrated Workflow for Chemical EOR Pilot Design: SPE paper 129865, in SPE Improved Oil Recovery Symposium, Tulsa, Oklahoma, USA, 24-28 April, SPE (ed.). DOI: https://doi.org/10.2118/129865-MS

Morvan M., Koetitz R., Moreau P., Pavageau B., Rivoal P., Roux B. (2008) A combinatorial approach for identification of performance EOR surfactants: SPE 113705, in SPE/DOE Improved Oil Recovery Symposium, Tulsa, Oklahoma, USA, 19-23 April, SPE (ed.). DOI: https://doi.org/10.2118/113705-MS

Negin C., Ali S., Xie Q. (2017) Most common surfactants employed in chemical enhanced oil recovery, Petroleum 3, 2, 197-211. DOI: https://doi.org/10.1016/j.petlm.2016.11.007

Oughanem R., Youssef S., Bauer D., Peysson Y., Maire E., Vizika O. (2015) A Multi-Scale Investigation of Pore Structure Impact on the Mobilization of Trapped Oil by Surfactant Injection, Transp Porous Med 109, 3, 673-692. DOI: 10.1007/s11242-015-0542-5

Oukhemanou F., Courtaud T., Morvan M., Moreau P., Mougin P., Féjean C., Pedel N., Bazin B., Tabary R., Tabary R. (2014) Alkaline-Surfactant-Polymer Formulation Evaluation In Live Oil Conditions: The Impact Of Temperature, Pressure And Gas On Oil Recovery Performance: SPE 169130, in SPE Improved Oil Recovery Symposium, Tulsa, Oklahoma, USA, 12-16 April, SPE (ed.). DOI: https://doi.org/10.2118/169130-MS

Queste S., Salager J.L., Strey R., Aubry J.M. (2007) The EACN scale for oil classification revisited thanks to fish diagrams, Journal of colloid and interface science $312,1,98-107$. DOI: 10.1016/j.jcis.2006.07.004

Reed R.L., Healy R.N. (1977) Some physicochemical aspects of microemulsion flooding: A Review, in Improved Oil Recovery by Surfactant and Polymer Flooding, D. O. Shah and R. S. Schechter (ed.), Academic Press, pp. 383-437.

Salager J.-L., Forgiarini A.M., Bullón J. (2013) How to Attain Ultralow Interfacial Tension and Three-Phase Behavior with Surfactant Formulation for Enhanced Oil Recovery: A Review. Part 1. Optimum Formulation for Simple Surfactant-Oil-Water Ternary Systems, J Surfact Deterg 16, 4, 449-472. DOI: 10.1007/s11743-013-1470-4

Sheng J.J. (2010) Optimum phase type and optimum salinity profile in surfactant flooding, Journal of Petroleum Science and Engineering 75, 1-2, 143-153. DOI: https://doi.org/10.1016/j.petrol.2010.11.005 
604 Sheng J. (2011) Modern chemical enhanced oil recovery: Theory and practice, Gulf Professional 605 Pub., Amsterdam Boston. ISBN: 978-1-85617-745-0.

606 Sheng J.J. (2014) A comprehensive review of alkaline-surfactant-polymer (ASP) flooding, Asia607 Pac. J. Chem. Eng. 9, 471-489. DOI: https://doi.org/10.1002/apj.1824

608 Stroock A.D., Dertinger S.K.W., Ajdari A., Mezic I., Stone H.A., Whitesides G.M. (2002) Chaotic 609 mixer for microchannels, Science 295, 5555, 647-651. DOI: 10.1126/science.1066238

610 Thomas S., Farouq Ali S.M. (1999) Status and Assessment of Chemical Oil Recovery Methods, 611 Energy Sources 21, 1-2, 177-189. DOI: https://doi.org/10.1080/00908319950015046

612 Thomas S. (2008) Enhanced Oil Recovery - An Overview, Oil \& Gas Science and Technology 613 Rev. IFP 63, 1, 9-19. DOI: https://doi.org/10.2516/ogst:2007060

614 Utada A.S., Lorenceau E., Link D.R., Kaplan P.D., Stone H.A., Weitz D.A. (2005) Monodisperse 615 double emulsions generated from a microcapillary device, Science 308, 5721, 537-541. DOI: $616 \quad 10.1126 /$ science.1109164 